\title{
A Bidirectional Study of the Earlier Acquisition of Dative Structures in English and Arabic
}

\author{
Anwar Saad Aljadani \\ Correspondence: Anwar Saad Aljadani, Arts and Humanities, King Abdulaziz University, Jeddah, Kingdom of Saudi \\ Arabia.
}

Received: January 14, 2019

doi:10.11114/ijce.v2i1.3967

\author{
Accepted: January 28, 2019 Online Published: January 31, 2019
}

URL: https://doi.org/10.11114/ijce.v2i1.3967

\begin{abstract}
This article conducts a bidirectional investigation of the earlier acquisition of dative structures in English and Arabic by Second Language (L2) learners. It reports on two dative structures: the Prepositional Dative (PD) structure and the Double Object Dative (DOD) structure, rating experiments (grammaticality judgment task) to test which dative structure is preferred earlier by L2 learners and whether L2 learners transfer their preferences relating to the two dative structures in the First Language (L1) to their L2. A total of 50 Arab learners of English and 40 English learners of Arabic were tested for the purpose of this study. It was observed that Arab learners of English preferred the PD structure over the DOD structure, whereas English learners of Arabic showed a slight preference for the use of the DOD structure; however, this observation is statistically insignificant. These findings indicate a lack of L1 influence, as all L2 learners preferred a dative structure that does not correspond to the preferred structure in their L1. Such findings could be consistent with the idea of the language acquisition process, as proposed by the Processability Theory, which implies that constructions that are easiest to process will be learned earlier than those that are harder to process despite the convergences between L1 and L2.
\end{abstract}

Keywords: dative structures, the prepositional dative structure, the double object dative structure, second language learners, process ability theory

\section{Introduction}

The acquisition of dative alternation captures the attention of linguists and highlights intriguing questions for them, such as the question about the earlier acquisition of either construction. A few researchers investigated the prior acquisition of dative alternation and found that the Prepositional Dative (PD) structure is learnt earlier than the Double Object Dative (DOD) structure. Mazurkewich (1984), for example, found that L2 learners of English acquire the PD structure first due to its markedness. Furthermore, Hawkins (1987) too observed that the PD structure is learnt before the DOD structure. To further illustrate, Anderssen et al. (2014) found that children preferred the PD structure to the DOD structure as the basic word order in various discourse contexts. Additionally, De Cuypere et al. (2014) found a subtle preference for the use of the PD structure among the German learners of English. The primary aim of this study is to explore which dative structure in Arabic and English is acquired earlier by L2 learners. To this end, the following research questions have been formulated: 1) Which dative structures would be preferred and easily acquired by L2 learners? 2) Are the preferences for either of the dative structures in L2 correlated with the preference for the corresponding structures in L1?

This article has been organised as follows: the second section of this paper provides a general background of the dative alternation in English and Arabic, followed by a brief summary of previous studies on the acquisition of the dative alternation; the succeeding section presents the experimental studies, following which the results and discussion have been outlined; the conclusion is presented at the end of the paper.

\section{General Background of Dative Structures in English and Arabic}

A number of English verbs appertain to a variety of complement types: the PD structure and the DOD structure, as exemplified in (1):

(1) a. Ann gave a book to David.

b. Ann gave David a book. 
The examples provided in (1) show what is generally known as the dative alternation. The PD structure is presented in (1a), and the DOD structure is presented in (1b). However, although the two sentences are almost synonymous, dative alternation is distinguished semantically and syntactically. The PD structure, as in (1a), is marked by free morpheme, whereas the DOD structure, as in (1b), is marked by word order.

Moreover, it has been observed that the syntactic productivity of the PD construction is wider than that of the DOD construction. This claim is supported by the fact that the majority of dative verbs that occur in a DOD construction can take the PD construction, whereas only certain dative verbs can take the DOD construction (Hawkins, 1987; Mazurkewich, 1984). However, some dative verbs require a recipient, as in (2a), while others require a benefactive, as in (2b). The possibility of one proposition, sometimes, excludes the other, as illustrated in (3):

(2) a. Ann gave a pen to Smith.

b. Ann baked a cupcake for Smith.

(3) a. Tamara built a new house for Bush.

b. * Tamara built a new house to Bush.

Interestingly, there are other English verbs that appear either with the PD structure or the DOD structure. Verbs such as demonstrate, deliver, describe, dictate and donate are only allowed to be used with the PD structure, as in (4). However, verbs such as ask, envy, cost and deny are allowed to take only the DOD structure, as shown in (5):

(4) a. Abel donated some money to Adam.

b. *Abel donated Adam some money.

(5) a. Tamara asked her friend a question.

b. * Tamara addressed a question to her friend.

The verbs that are allowed to take only one type of dative structure are known as non-alternating verbs.

In Arabic, numerous verbs are allowed to appear with both the PD and DOD structures, as shown in example (6):

(6) a. a. a أعطى عمرُ الكتابَ إلى على

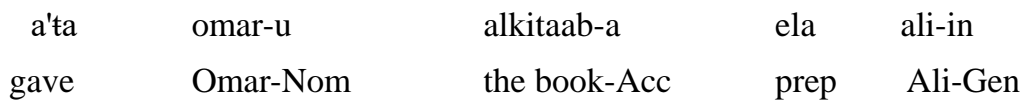

'Omar gave the book to Ali.'

b. أعطى عمرُ عليًا الكتابت

$\begin{array}{llll}\text { a'ta } & \text { omar-u } & \text { ali-an } & \text { alkitaab-a } \\ \text { gave } & \text { Omar-Nom } & \text { Ali-Acc } & \text { the book-Acc }\end{array}$

'Omar gave Ali the book.'

Example (6a) shows the Arabic PD structure, whereas example (6b) illustrates the Arabic DOD structure. The goal argument in the PD structure is marked by the genitive case, as it is prefixed by benefactive/allative preposition ela 'to'. However, the Arabic DOD structure's arguments and the theme argument in the PD structure are marked by the accusative case.

\section{A Brief Summary of Previous Studies of the Acquisition of Dative Structures}

The acquisition of dative alternation has received much attention since the 1980s, especially from the perspective of generative grammar. A remarkable number of studies, such as that of Mazurkewich (1984), have been devoted to the acquisition of dative alternation by L2 learners. The participants of Mazurkewich's (1984) study included 45 French students, 38 Inuktitut students and two control groups consisting of native English speakers. This research found that the unmarked structure (the PD) was acquired earlier than the marked structure (the DOD), as predicted. This difficulty of order supports the lexical approach in which the acquisition order is determined by a theory of markedness associated with Universal Grammar (UG), which differentiates between 'unmarked' and 'marked' in terms of complexity, nature, frequency and cross-linguistic occurrence. The term 'unmarked' has come to refer to the rules of core grammar, which are expected to be easier to acquire on the basis of minimal exposure to L2 grammar, given that they are simple, natural, frequent and allowed in most languages. On the other hand, the term 'marked' is generally understood to mean the rules outside the core of grammar. These rules are not only expected to be harder to acquire but also expected to be acquired on the basis of positive evidence of their availability in L2 grammar, owing to their complexity, lower frequency and absence of use in all the world's languages (Chomsky, 1981). The significance of this theory for language acquisition was demonstrated by Mazurkewich (1985: 16) who stated the following: 
The prediction made by such a theory is that as soon as the linguistic input triggers a learner's awareness of the existence of a core rule in the grammar, that rule not only would be learned easily, but it would be learned on the basis of minimal exposure to that language as it is predicted of UG. In the case of non-core or marked rules, the prediction is that they would have to be learned on the basis of positive evidence of their existence in that grammar.

Hawkins (1987) re-examined the acquisition of English dative alternations by French learners. Two types of questionnaires were prepared for this study: a grammaticality judgment test similar to Mazurkewich's (1981) task and a sentence-construction test (a production task). Hawkins, however, included a wider range of verbs than Mazurkewich. The results of this study showed that the participants judged the PD construction to be more acceptable than the DOD construction. Hawkins' (1987) findings also showed that the participants found to-dative verbs more acceptable than for-dative verbs. Furthermore, they distinguished between the to-and for-datives, relying on whether the indirect object was definite or indefinite. To-dative verbs seemed to be acceptable with either definite or indefinite direct objects, whereas for-dative verbs with a definite direct object in the DOD construction seemed to be less acceptable. Hawkins (1987) argued that markedness cannot be considered as the only element in the acquisition of dative alternation; it represents only one stage of the acquisition process. The author also found that the acquisition of English dative alternation as L2 is a complicated phenomenon, which cannot be interpreted by the markedness theory alone; however, it can possibly be explained in terms of learning complexity, in which learners proceed from an initial broad generalisation about the dative alternation, which is subsequently refined by the addition of syntactic/morphological features to their grammar.

Hawkins (1987) also posited that an 'operating principle' or 'one-to-one principle' (one construction, one meaning) plays an increasingly important role in the earlier acquisition of the PD construction than the DOD construction. This principle claims that learners think, until they receive positive evidence to the contrary, that each surface construction is paired with exactly one meaning. In fact, dative alternation violates this principle. Nonetheless, learners initially believe that the surface difference corresponds to a certain underlying difference, and the feature they seem to single out is pronominal; this implies that one of the surface structures is initially pronominal, and the other includes Noun Phrases (NP).

Another study by De Cuypere et al. (2014) investigated the acquisition of English dative alternation by Russian native speakers. An acceptability judgment test was conducted to investigate the choice of one dative structure before the other. A subtle preference for the use of the PD structure was revealed, and this was attributed to the language acquisition process, as suggested by the Processability Theory (PT), which implies that constructions that are easiest to process will be learned earlier than those that are harder to process despite the convergences between L1 and L2.

Furthermore, Jäschke and Plag (2016) examined the acquisition of English dative alternation by native German speakers. Their aim was to investigate advanced native German speakers' preference of dative structures - PD or DOD - in English. Additionally, they investigated the extent to which German learners' preferences are affected by the same constraints that have been assumed to affect L1 learners' preferences. It was revealed that the PD construction was slightly more preferred by the participants. The authors that L2 learners are affected by the same factors, such as animacy of the recipient, pronominality of theme and definiteness of the recipient, as L1 learners, but to a lesser degree. Their results suggest that $\mathrm{L} 2$ learners do not make use of probabilistic constraints initially, despite the constraints being effective in L1, and only gradually develop sensitivity towards the constraints that govern the preference of the two structures.

\section{The experimental Studies}

\subsection{Participants}

As this study has adopted a bidirectional approach to investigate the acquisition of dative structure, it consists of two parts: one studying Arab learners' acquisition of English (the English study) and another studying English learners' acquisition of Arabic (the Arabic study). The English study was conducted with two groups. the first group comprised of 50 Arab learners of English who were further divided into two groups based on their proficiency levels: pre-intermediate and upper-intermediate. The second group - the control group - consisted of 10 native speakers. The Arabic study compared a group of English learners to a group of Arabic controls. The learner group consisted of 40 English learners of Arabic who exhibited two proficiency levels: pre-intermediate and upper-intermediate. The control group comprised of 10 Arabs.

\subsection{Materials}

The participants in each study were given written grammaticality judgment tasks with pictures, followed by two dative sentences. The questionnaire involved 12 pictures, each picture describing a verb in two different constructions: the PD 
and the DOD. The different constructions are shown in the tables below. These 12 verbs were classified into two classes; the first class had five verbs (give, sell, hand, tell and show) and the second class had seven (read, write, pay, throw, kick, toss and shoot). Each sentence was followed by a three-point Likert scale from 1 (bad example) through 2 (not sure) to 3 (good example).

Table 1. Examples of the two different structures with 'tell'

\begin{tabular}{|c|c|c|}
\hline The abbreviation of each structure & Language & Example \\
\hline \multirow{2}{*}{ PD1 } & Arabic & أخبرَ محمدٌ القصة لعلي. \\
\hline & English & Mohammed told the story to Ali \\
\hline \multirow{2}{*}{ DOD1 } & Arabic & أخبرَ محمدٌ عليًا القصةُ. \\
\hline & English & Mohammed told Ali the story \\
\hline
\end{tabular}

\section{Results and Discussion}

5.1 English Study

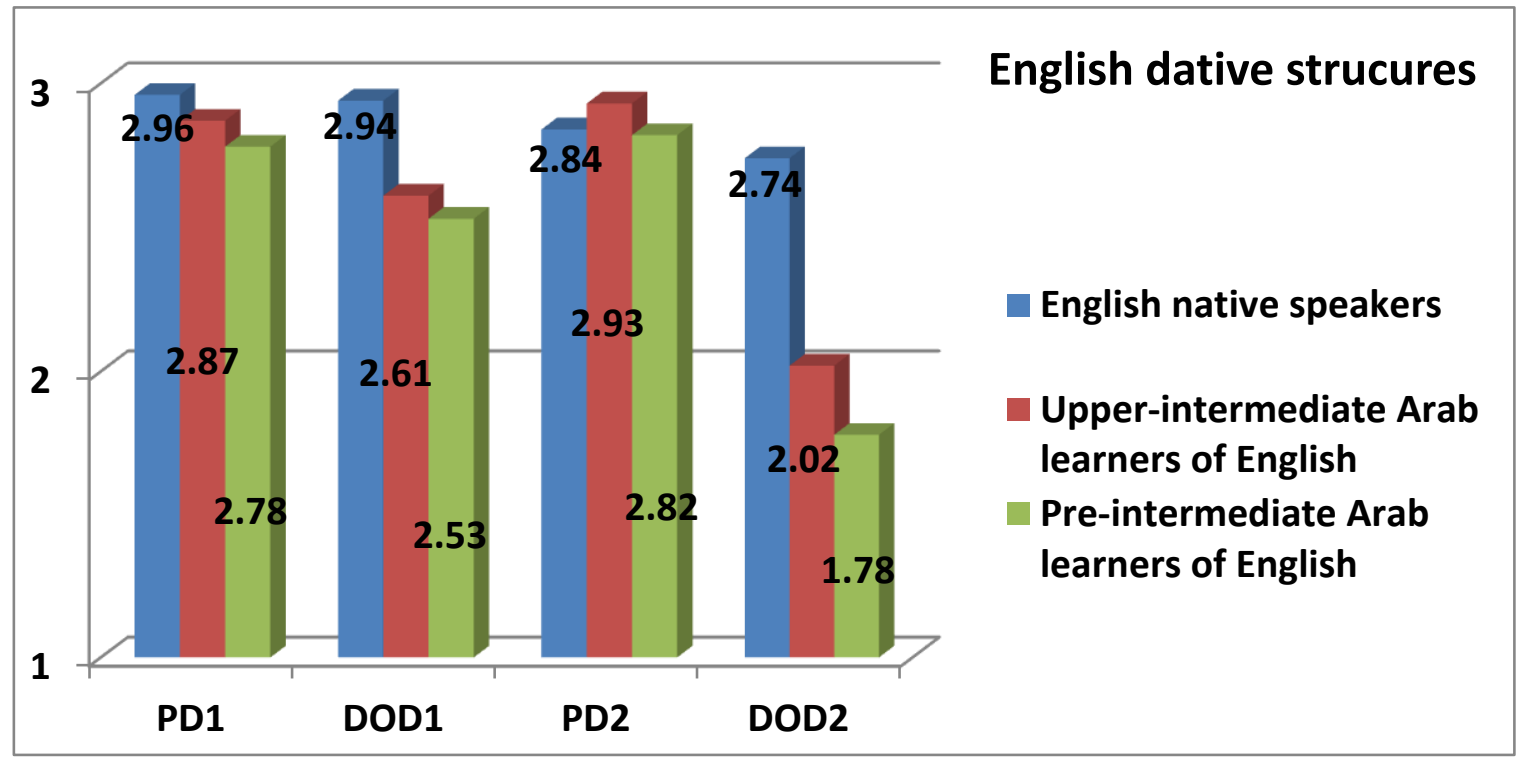

Figure 1. The mean responses on the assessments of English dative structures

Figure 1 demonstrates the mean responses of native Arabic speakers with respect to the acquisition of English dative structures. It is obvious from the mean values displayed in this figure that all the participants accepted the PD constructions, with groups 1 and 2 as excellent examples of English. What is also notable from the data revealed in Figure 1 is that all the participants judged the DOD1 construction as a good English structure. Another significant observation that can be made from Figure 1 is that the Arab learners of English, even at the upper-intermediate level, did not accept the DOD2 construction, as evidenced by their ratings, which were not as high as those of the native speakers (2.02: 1.78 vs. 2.74). To answer the question of which dative structure is acquired earlier among verb groups by native speakers of Arabic, a paired samples t-test should be conducted. Table 2 shows another difference between the DOD1 and the PD1 patterns. Although both structures are grammatical in L1, the upper-intermediate group accepted the PD1 structure more than the DOD1 structure ( 2.87 vs. $2.61, \mathrm{t}=-3.25, \mathrm{df}=24, \mathrm{p}=.003)$. However, there was no disparity among the control group ( 2.94 vs. $2.96, \mathrm{t}=-.318, \mathrm{df}=9, \mathrm{p}=.758)$ and the pre-intermediate group ( $2.53 \mathrm{vs}$. $2.78, \mathrm{t}=-2.03, \mathrm{df}=24, \mathrm{p}=.053)$ in the comparison between the PD1 and DOD1 structures. 
Table 2. The comparison between DOD1 and PD1 in English by using paired-samples t-tests

\begin{tabular}{|c|c|c|c|c|c|c|c|}
\hline \multicolumn{2}{|l|}{ Participants } & & & & \multirow[t]{2}{*}{$\mathrm{t}$} & \multirow[t]{2}{*}{$\mathrm{df}$} & \multirow[t]{2}{*}{ sig } \\
\hline Groups & $\mathrm{N}$ & Structure & Means & $\mathrm{SD}$ & & & \\
\hline \multirow[t]{2}{*}{ English native speakers } & \multirow[t]{2}{*}{10} & DOD1 & 2.94 & .13499 & \multirow[t]{2}{*}{-.318} & \multirow[t]{2}{*}{9} & \multirow[t]{2}{*}{.758} \\
\hline & & PD1 & 2.96 & .12649 & & & \\
\hline \multirow{2}{*}{$\begin{array}{l}\text { Upper-intermediate Arab } \\
\text { learners of English }\end{array}$} & \multirow[t]{2}{*}{25} & DOD1 & 2.61 & .42000 & \multirow[t]{2}{*}{-3.25} & \multirow[t]{2}{*}{24} & \multirow[t]{2}{*}{.003} \\
\hline & & PD1 & 2.87 & .30485 & & & \\
\hline \multirow{2}{*}{$\begin{array}{l}\text { Pre-intermediate Arab } \\
\text { learners of English }\end{array}$} & \multirow[t]{2}{*}{25} & DOD1 & 2.53 & .41921 & \multirow[t]{2}{*}{-2.03} & \multirow[t]{2}{*}{24} & \multirow[t]{2}{*}{.053} \\
\hline & & PD1 & 2.78 & .48963 & & & \\
\hline
\end{tabular}

( Note: $\mathrm{SD}=\mathrm{Std}$. Deviation; $\mathrm{t}=\mathrm{t}$-test score; $\mathrm{df}=$ degree of freedom; $\mathrm{sig}=$ value )

While comparing the DOD2 and PD2 structures, a large variation was observed, as Table 3 indicates. The experimental groups showed a preference for the PD2 pattern (2.93 vs. 2.82) over the DOD2 pattern (2.02 vs. 1.78). This significant disparity between the upper-intermediate group $(\mathrm{t}=-9.85, \mathrm{df}=24, \mathrm{p}=.000)$ and the pre-intermediate group $(\mathrm{t}=-5.96$, $\mathrm{df}=24, \mathrm{p}=.000$ ) with respect to the preference of structures, as Table 3 shows, stems from the high preference for the PD2 construction over the DOD2 construction. However, statistical analysis showed no significant disparity among the native speakers $(\mathrm{t}=-.891, \mathrm{df}=9, \mathrm{p}=.396)$ with respect to the preference for these two structures, indicating that they were remarkably accepted by this group.

Table 3. The comparison between DOD2 and PD2 in English by using paired-sample t-tests

\begin{tabular}{|c|c|c|c|c|c|c|c|}
\hline \multicolumn{2}{|l|}{ Participants } & & & & \multirow[t]{2}{*}{$\mathrm{t}$} & \multirow[t]{2}{*}{ df } & \multirow[t]{2}{*}{ sig } \\
\hline Groups & $\mathrm{N}$ & structure & means & SD & & & \\
\hline \multirow[t]{2}{*}{ English native speakers } & \multirow[t]{2}{*}{10} & DOD2 & 2.74 & .24232 & \multirow{2}{*}{-.891} & \multirow[t]{2}{*}{9} & \multirow[t]{2}{*}{.396} \\
\hline & & PD2 & 2.84 & .21816 & & & \\
\hline \multirow{2}{*}{$\begin{array}{l}\text { Upper-intermediate Arab } \\
\text { learners of English }\end{array}$} & \multirow[t]{2}{*}{25} & DOD2 & 2.02 & .50228 & \multirow{2}{*}{-9.85} & \multirow[t]{2}{*}{24} & \multirow[t]{2}{*}{.000} \\
\hline & & PD2 & 2.93 & .12544 & & & \\
\hline \multirow{2}{*}{$\begin{array}{l}\text { Pre-intermediate Arab learners } \\
\text { of English }\end{array}$} & \multirow[t]{2}{*}{25} & DOD2 & 1.78 & .57542 & \multirow[t]{2}{*}{-5.96} & \multirow[t]{2}{*}{24} & \multirow[t]{2}{*}{.000} \\
\hline & & PD2 & 2.82 & .43918 & & & \\
\hline
\end{tabular}

( Note: $\mathrm{SD}=\mathrm{Std}$. Deviation; $\mathrm{t}=\mathrm{t}$-test score; $\mathrm{df}=$ degree of freedom; sig= value )

One interesting finding of the current study was that Arab learners of English accepted the PD1 structure (e.g., Noah sold the car to Billy) earlier and more than the DOD1 structure (e.g., Noah sold Billy the car) (2.87 and 2.78 vs. 2.61 and 2.53). Moreover, PD2, as a structure, was more positively judged (e.g., George paid ten pounds to Jay) than the DOD2 (e.g., George paid Jay ten pounds) (2.93 and 2.82 vs. 2.00 and 1.78). These results are consistent with those of previous observational studies, viz. PD construction is acquired early by L2 learners compared to DOD construction. A well-known example of these studies is the research by Mazurkewich $(1981,1984,1985)$, which found that the PD structure is more easily acquired by L2 learners. She investigated the theory of markedness being associated with UG, which claims that a few rules are marked while the rest are unmarked. According to her interpretation, the PD structure is considered an unmarked rule, i.e. core grammar. Consequently, such a structure is predicted to be acquired straightforwardly on the basis of its early exposure to the L2 input. However, the DOD structure belongs to a marked rule class, which is not considered to be core grammar. Such rules are expected to be hard to learn; thus, learners should be given positive evidence to assist them in acquiring such rules. She also argued that the PD structure is straightforwardly acquirable due to its wide productivity. This generally means that all verbs occurring in a DOD structure must allow a PD structure, but not necessarily vice versa (Hawkins, 1987).

Another study compatible with the finding of the current study on the earlier acquisition of the PD structure was conducted by Hawkins (1987). However, his interpretation differed from that of Mazurkewich, as he made markedness only a point in the second stage of the acquisition of dative alternation. He also believed that dative alternation can be acquired through the progressive introduction of syntactic features into the L2 learners' grammar. This will enable them to start by differentiating between the pronominal and lexical objects, followed by distinguishing verbs that take the to-PP from those that take the for-PP, whereas late learners will distinguish native verbs from Latinate verbs.

Another study that revealed that the PD structure is acquired before the DOD structure was conducted by Mykhaylyk et 
al. (2013). They investigated the acquisition of English dative alternation by Russian and Ukrainian adults and 3-6-year-old children. They found that children preferred the PD structure. Furthermore, they stated that processing difficulties, the complexity of the syntactic structure or pronominality could be a possible explanation for the lack of preference for the DOD structure in the acquisition of English dative alternation in L1.

Anderssen et al. (2014) looked at the acquisition of Norwegian dative alternations by Norwegian children. They explored the pragmatic principle (givenness) that led native Norwegian speakers to syntactically choose one word order over another. They found that children preferred the PD structure to the DOD structure as the basic word order in various discourse contexts.

De Cuypere et al. (2014) investigated the acquisition of English dative alternation by Russian native speakers. An acceptability judgement test was conducted to investigate the choice of one dative structure before the other. A subtle preference for the use of the PD structure was revealed, which was attributed to the language acquisition process, as suggested by the PT formulated by Pienemann (1998), which implies that constructions that are easiest to process will be learned earlier than harder constructions despite convergences between L1 and L2.

Jäschke and Plag (2016) examined the acquisition of English dative alternation by native German speakers. Their primary aim was to investigate the preference of dative structures - the PD or the DOD - in English by advanced native German speakers. They also investigated the extent to which German learners' preferences are affected by the same constraints that have been assumed to affect L1 learners' preferences. It was revealed that PD construction was slightly more preferred by the participants. The authors argued that L2 learners are affected by the same factors, such as animacy of the recipient, pronominality of theme and definiteness of the recipient, as L1 learners, but to a lesser degree. Their results suggest that, initially, L2 learners do not make use of probabilistic constraints, despite the constraints being effective in L1, and only gradually develop sensitivity towards the constraints that govern the preference of the two structures.

The finding of this study lends evidence to support the claim that the PD structure is acquired earlier than the DOD structure, as the learners in this study showed a slightly increased preference for the PD structure even though the DOD structure is more popular in their L1. However, the Arab learners accepted both the PD1 structure (2.87 vs. 2.78) and the DOD1 structure (2.61 vs. 2.53). This acceptance may be due to the availability of both structures in their L1. The preference for the PD structure over the DOD structure could be attributed to a lack of L1 transfer, as the DOD structure is preferred in L1. The lack of L1 influence in this study might have arisen due to the methodology that was chosen to collect the data (written judgment test by pre-intermediate and upper-intermediate learners of English). First, the finding of this study could possibly be attributed to the low proficiency level of the current L2 learners or the late acquisition of dative alternation. Furthermore, more advanced Arab learners of English may perhaps make the transfer more obvious. Second, the data for this study was gathered only through a written test. However, the results may differ if other tests, such as a translation task in the acquisition of English dative alternation by native Arabic speakers, are used. However, the lack of influence on performance will possibly contribute to overruling by exhibiting a general preference for the PD structure. The general preference for the PD structure could be a type of confirmation for certain ideas, such as the markedness theory. The finding of the English study - PD construction is learnt earlier than the DOD structure - is consistent with those of Mazurkewich and Hawkins. Their interpretation was that markedness is a key aspect in the acquisition of dative alternation along with other elements such as L1 transfer, overgeneralisation or positive evidence. Thus, the results of the current study may be interpreted as evidence of the importance of markedness in the acquisitional process of dative alternation in $\mathrm{L} 2$.

The findings of this study are also consistent with the idea of the language acquisition process, as proposed by the PT. The PT implies that constructions that are easier or easiest to process will be learned earlier than constructions that are harder despite convergences between L1 and L2.

With respect to the preference of the English PD structure to the DOD structure by Arab learners, it is to be noted that Arabic, similar to German and Russian, allows dative alternation and a variety of word orders that reflect principles such as pronoun-before-noun. Such principles are similar to the ones in English, as outlined in the present study as well as in the one by Jäschke and Plag (2016) and De Cuypere et al (2014). The question is whether the preference structure in L1 is transferred or whether L2 principles are acquired. Combining the findings of the two previous studies and the current study, it may be possible to indicate that the principles are acquired rather than transferred. While the beginner Russian learners of De Cuypere et al.'s (2014) study did not follow the ordering of their L1 and showed a preference for the easily processable PD structure, the advanced German learners of Jäschke and Plag's (2016) study showed only a slightly increased preference for the PD structure and, at the same time, followed a number of factors, which the native speakers too follow. The pre-intermediate and the upper-intermediate Arab learners of this study preferred the PD structure to the DOD structure, which could possibly indicate that these learners were influenced by the type of dative 
verbs that are present in L1. This claim is supported by the fact that the Arab learners significantly preferred the PD2 structure (2.93 vs. 2.82 ) to the DOD2 structure (2.02 vs. 1.78), as Table 3 shows. This significant preference may owe to the fact that the DOD2 structure is not fully acquired by current Arab learners of English due to its ungrammaticality in their L1.

Overall, the preference of the PD structure to the DOD structure in the current study may be interpreted as evidence of the importance of markedness in the acquisitional process of dative alternation in L2. The PD structure is easier to learn than the DOD structure. L1 transfer can be observed in the preference of the PD2 structure over the DOD2 structure, as the DOD2 structure is ungrammatical in L1 grammar. These learners were influenced by their L1 and, thus, ignored the grammaticality of the DOD2 structure due to its absence in their L1.

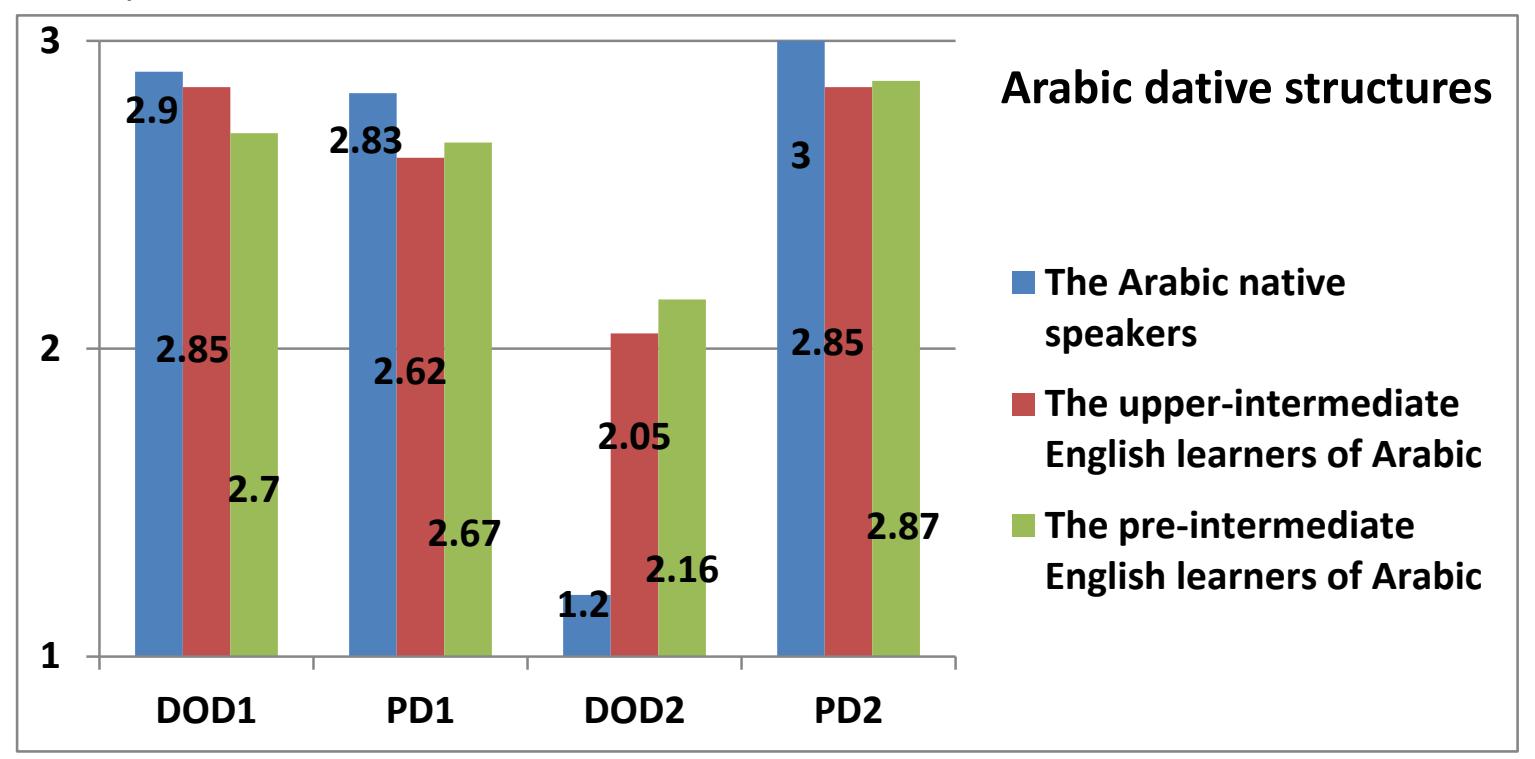

Figure 2. The mean responses on the assessments of the Arabic dative structures

\subsection{Arabic Study}

Figure 2 displays the mean responses of English native speakers on the acquisition of Arabic dative constructions. It is obvious from the mean values displayed in the figure that all the participants positively judged both the PD1 construction and the PD2 construction even though the English learners' rates are not as high as the Arabic native speakers' rates. It is certainly apparent that all the participants readily accepted the DOD1 structure as a completely natural sentence. Moreover, the most significant finding to be noticed from Figure 2 is that the experimental participants accepted the DOD2 structure as a well-formed example of the Arabic language, which it is not. As evident from the figure, all structures received a positive rating. However, the aim of this study is to find out which dative structure is acquired earlier. To do so, the paired samples t-test should be conducted. What is interesting is that the participants appeared to show more of a preference for the rating of the DOD1 structure than the PD1 structure. However, this slight preference did not reveal any significant results among the three groups, as shown in Table 4.

Table 4. The comparison between the assessments of the DOD1 and the PD1 structures in Arabic

\begin{tabular}{|c|c|c|c|c|c|c|c|}
\hline \multicolumn{2}{|l|}{ Participants } & & & & \multirow{2}{*}{$\mathrm{t}$} & \multirow{2}{*}{$\mathrm{df}$} & \multirow{2}{*}{ sig } \\
\hline Groups & $\mathrm{N}$ & structure & means & $\mathrm{SD}$ & & & \\
\hline \multirow{2}{*}{ Arabic native speakers } & \multirow{2}{*}{10} & DOD1 & 2.90 & .16997 & \multirow{2}{*}{.805} & \multirow{2}{*}{9} & \multirow{2}{*}{.442} \\
\hline & & PD1 & 2.83 & .16235 & & & \\
\hline \multirow{2}{*}{$\begin{array}{l}\text { Upper-intermediate English } \\
\text { learners of Arabic }\end{array}$} & \multirow{2}{*}{20} & DOD1 & 2.58 & .51463 & \multirow{2}{*}{-.343} & \multirow{2}{*}{19} & \multirow{2}{*}{.736} \\
\hline & & PD1 & 2.62 & .20859 & & & \\
\hline \multirow{2}{*}{$\begin{array}{c}\text { Pre-intermediate English learners } \\
\text { of Arabic }\end{array}$} & \multirow{2}{*}{20} & DOD1 & 2.70 & .31456 & \multirow{2}{*}{.249} & \multirow{2}{*}{19} & \multirow[t]{2}{*}{.806} \\
\hline & & PD1 & 2.67 & .34363 & & & \\
\hline
\end{tabular}

( Note: $\mathrm{SD}=\mathrm{Std}$. Deviation; $\mathrm{t}=\mathrm{t}$-test score; $\mathrm{df}=$ degree of freedom; sig= value )

This study also aimed to identify which Arabic dative structures were preferred and easily acquired by native English 
speakers. Based on previous findings, such as those of Hawkins (1987), Mykhaylyk et al. (2013) and Jäschke and Plag (2016), all experimental participants were expected to first acquire the PD structure in Arabic.

With respect to this research question, it was somewhat surprising that the English learners of Arabic acquired the DOD1 structure (e.g.. Majdi gave Anwar the book) earlier than the PD1 structure (e.g., Majdi gave the book to Anwar) (2.85 and 2.70 vs. 2.62 and 2.67). These unexpected results do not corroborate the observation of previous studies, such as those of Mazurkewich (1981, 1984, 1985), Hawkins (1987), Mykhaylyk et al. (2013), Anderssen et al. (2014), De Cuypere et al (2014) and Jäschke and Plag (2016), all of whom revealed that PD construction is acquired earlier than DOD construction by $\mathrm{L} 2$ learners.

Thus, the current finding is rather contradictory to the previous findings, as the DOD1 structure is preferred to the PD1 structure. This rather contradictory result could be attributed to the fact that the Arabic DOD1 structure is an unmarked structure, which is easily acquired in an early exposure to Arabic, whereas the PD1 structure is less frequent compared to the DOD1 structure, as the native speakers accepted the DOD1 structure more easily than the PD1 structure with alternating verbs. This finding may provide evidence for the idea of the language acquisition process, as offered by the PT, which implies that structures that are easier or easiest to process will be acquired earlier than structures that are harder to process despite convergences between L1 and L2. Another possible explanation for this finding is that these learners acquire their Arabic by attending certain Arabic courses to explicitly learn some L2 grammar, and textbooks of these courses included alternating verbs. This finding may also be attributed to the subgroup of the PD structure and the limited number of dative verbs, with the majority of Arabic grammar textbooks concentrating on the DOD structure more than the PD structure in dative alternation lessons. Such concentration may lead these learners to devote more attention to the DOD structure than the PD structure with alternating verbs.

Moreover, this preference may be due to the availability of both structures in L1. The preference of the DOD1 structure over the PD1 structure could possibly be caused due to a lack of L1 transfer, as the PD1 structure is preferred in L1. The lack of L1 influence in this study might have arisen due to the methodology that was chosen to collect the data (written judgment test by pre-intermediate and upper-intermediate learners of Arabic). First, the finding of this study could possibly be attributed to the low proficiency level of L2 learners or the late acquisition of dative alternation. Furthermore, more advanced English learners of Arabic may perhaps make the transfer more obvious. Second, the data for this study was gathered only through a written test. Thus, the results may differ if another actual or oral test is conducted to investigate the acquisition of Arabic dative alternation by native Arabic speakers.

An additional comparison was conducted between the assessment of PD2 (e.g., Hani read the report to Nasser) and DOD2 (e.g., Hani read Nasser the report) structures. It was revealed that even though the DOD structure is unmarked in the formal sense of structural markedness, as the DOD2 structure is actually ungrammatical in Arabic, L2 learners were aware of its ungrammaticality, as they rated the DOD2 structure lower than the BPD2 structure, and they rated the PD2 structure as clearly grammatical (2.85/2.78).

It is worth mentioning that the preference of the PD structure over the DOD structure and vice versa in the current studies could be related to discourse principles such as given and new information, as suggested by Chang (2004). Moreover, it may be related to the type of NP (Aissen 1999; O'Connor et al., 2004). The type of NP is summarised in the so-called harmonic alignment pattern. An extra factor that may affect the occurrence of a specific structure in a certain context is syntactic weight. This factor is sometimes known as the end-weight principle (Wasow \& Arnold, 2003). These limitations ought to be investigated in future studies.

\section{Conclusion}

The current study was conducted to answer two research questions. The first question pertained to which dative structures are preferred and easily acquired by L2 learners. It was revealed that Arab learners of English acquire PD1 construction earlier than DOD1 construction. However, English learners of Arabic acquire DOD1 construction easier than PD1 construction. This difference may be due to the unmarkedness of each construction in their L2 and the language acquisition process proposed by PT. PD1 construction is the unmarked construction in English while DOD1 construction is the unmarked construction in Arabic. Consequently, the English PD1 structure and the Arabic DOD1 structure should be preferred and acquired earlier. It should be noted that the PD2 was acquired before the DOD2 construction by all L2 learners. The observed correlation between L2 English learners and L2 Arabic learners with respect to the early acquisition of PD2 construction may be explained as follows: L2 English learners acquire this construction early due to its unmarkedness and the language acquisition process, whereas L2 Arabic learners acquire it due to the ungrammaticality of the DOD2 in their L2 grammar. Secondly, it is investigated whether the preferences for either of the dative structures in L2 are associated with the preference for the corresponding structures in L1. It was found that L2 learners lacked L1 influence to some extent, as all of them preferred a dative structure that does not correspond to the preferred structure in L1. Further research should examine other factors, such as discourse principles, 
the type of NP and the end-weight principle, that may play a role in the preference of either structure. Furthermore, these studies should investigate whether the lack of L1 further decreases as language proficiency increases.

\section{References}

Aissen, J. (1999). Markedness and subject choice in Optimality Theory. Natural Language \& Linguistic Theory, 17, 673-711. https://doi.org/10.1023/A:1006335629372

Anderssen, M., Rodina, Y., Mykhaylyk, R., \& Fikkert, P. (2014). The acquisition of the dative alternation in Norwegian. Language Acquisition, 21, 72-102. https://doi.org/10.1080/10489223.2013.864296

Chang, L. H. (2004). Discourse effects on EFL learners' production of dative constructions. Journal of National Kaohsiung University of Applied Sciences, 33, 145-170.

Chomsky, N. (1981). A Note on Non-control PRO. Journal of Linguistic Research, 1, 1-11.

De Cuypere, L., De Coster, E., \& Baten, K. (2014). The acquisition of the English dative alternation by Russian foreign language learners. PHRASIS (GENT): Studies in language and literature, 187-212.

Hawkins, R. (1987). Markedness and the acquisition of the English dative alternation by L2 speakers. Second Language Research, 3, 20-55.

Jäschke, K., \& Plag, I. (2016). The Dative alternation in German-English Interlanguage. Studies in Second Language Acquisition, 38, 2016. https://doi.org/10.1017/S0272263115000261

Mazurkewich, I. (1981). Second language acquisition of the dative alternation and markedness: the best theory.

Mazurkewich, I. (1984). The acquisition of the dative alternation by second language learners and linguistic theory. Language learning, 34, 91-108. https://doi.org/10.1111/j.1467-1770.1984.tb00997.x

Mazurkewich, I. (1985). Syntactic markedness and language acquisition. Studies in second language acquisition, 7 , 15-35. https://doi.org/10.1017/S0272263100005131

Mykhaylyk, R., Rodina, Y., \& Anderssen, M. (2013). Ditransitive constructions in Russian and Ukrainian: Effect of givenness on word order. Lingua, 137, 271-289. https://doi.org/10.1016/j.lingua.2013.10.001

O’Connor, M. C., Anttila, A., Fong, V., \& Maling, J. (2004). Differential possessor expression in English: Re-evaluating animacy and topicality effects. Annual Meeting of the Linguistic Society of America, January, 2014, 9-11.

Pienemann, M. (1998). Language processing and second language development: Processability theory, John Benjamins Publishing. https://doi.org/10.1075/sibil.15

Wasow, T., \& Arnold, J. (2003). Post-verbal constituent ordering in English. Topics in English Linguistics, 43, 119-154. https://doi.org/10.1515/9783110900019.119

\section{Copyrights}

Copyright for this article is retained by the author(s), with first publication rights granted to the journal.

This is an open-access article distributed under the terms and conditions of the Creative Commons Attribution license which permits unrestricted use, distribution, and reproduction in any medium, provided the original work is properly cited. 